\title{
Some Fundamental Issues and Verification of 3DEC in Modeling Wave Propagation in Jointed Rock Masses
}

\author{
X. F. Deng $\cdot$ J. B. Zhu $\cdot$ S. G. Chen $\cdot$ \\ J. Zhao
}

Received: 10 October 2011/ Accepted: 23 June 2012/Published online: 18 July 2012

(C) Springer-Verlag 2012

Keywords 3DEC - Wave propagation - Rock joints . Rock mass - Mesh size · Joint orientation · Joint set

\section{Introduction}

Discontinuities in rock masses greatly influence stress wave transmission. Theoretical and experimental studies on wave propagation across joints have been extensively studied (e.g., Kendall and Tabor 1971; Schoenberg 1980; Pyrak-Nolte et al. 1990; Zhao and Cai 2001; Zhao et al. 2006a, b; Perino et al. 2010; Li and Ma 2010; Li et al. 2010), focusing on the effects of joint stiffness, incident angles, number of joints, and joint spacing on wave propagation.

Compared with theoretical and experimental studies, numerical modeling provides a convenient, economical approach to study wave propagation across a jointed rock mass, especially for complicated cases where theoretical solutions are impossible to obtain and experiments are difficult to conduct, such as wave propagation in a rock mass containing several intersecting joint sets and involving multiple tunnel excavation and underground explosions (Zhao et al. 1999).

X. F. Deng · S. G. Chen

MOE Key Laboratory of Transportation Tunnel Engineering, Southwest Jiaotong University, Chengdu 610031, China

X. F. Deng $(\bowtie) \cdot$ J. B. Zhu $\cdot$ J. Zhao

Ecole Polytechnique Fédérale de Lausanne (EPFL), School of Architecture Civil and Environmental Engineering, Laboratory for Rock Mechanics (LMR), 1005 Lausanne, Switzerland

e-mail: xifei.deng@epfl.ch
Before performing numerical modeling on complicated cases, benchmarking modeling must be performed first to validate the numerical code through comparison with theoretical solutions or experiment results. For a jointed rock mass excited by dynamic load, Lemos (1987) performed a study on $\mathrm{S}$ wave attenuation across a single joint with Coulomb slip behavior using UDEC. Brady et al. (1990) performed UDEC modeling on the slip of a single joint under an explosive line source. Chen et al. (2000a) verified the capability of UDEC to model the responses of jointed rock masses under explosion loading. Zhao et al. (2008) carried out numerical studies of $\mathrm{P}$ wave propagation across multiple non-linearly deformable joints with UDEC. Lei et al. (2007) studied 2D compressive wave propagation through a set of parallel joints in rock masses. Zhu et al. (2011a) verified the capability of UDEC to model wave transmission across rock joints and performed a numerical study on wave transmission across jointed rock masses with UDEC, where multiple joint sets exist. Barla et al. (2010) studied the stability of an underground water storage cavern in static and dynamic conditions with UDEC. The capability of other distinct models to study wave propagation in jointed rock masses has also been verified through similar comparisons, e.g., DDA and DLSM (Jiao et al. 2007; Zhu et al. 2011b).

Most of the numerical modeling studies on wave propagation across rock joints were performed by $2 \mathrm{D}$ code UDEC, which treats rock mass as an assembly of discrete blocks and joints as interfaces between the blocks (Cundall 1971). However, in 2D numerical modeling, it is difficult to fully represent joints, because joint planes exist in a 3D space. When there are multiple intersecting joints or underground structures, e.g., tunnels and caverns, 2D modeling cannot accurately express the spatial configuration of joints and underground structures. 3D Distinct 
Element Code (3DEC) is a 3D numerical code based on the extensively tested numerical formulation used by the UDEC. It should be an appropriate tool to model wave propagation in complicated 3D jointed rock mass. However, relatively little work has been done with 3DEC on this specific topic.

This study aimed to verify the capability of 3DEC to model wave propagation across rock joints in 3D space and was focused on analyzing the effects of mesh size, joint geometry, joint stiffness, wave type and frequency, and incident angle on wave propagation. For further verification, a case study of a large-scale decoupled explosion test was performed with 3DEC where the numerical modeling results were compared to the test data and predictions from empirical formula.

\section{2D Equivalence of 3D Plane Wave Propagation Across a Single Joint and a Joint Set}

For a random plane in a given 3D rectangular coordinate system, as shown in Fig. 1a, it is assumed that the wave incidence is in the $\mathrm{Z}$ direction. By rotating about the $\mathrm{Z}$-axis, the strike of the plane will be parallel to the $\mathrm{Y}^{\prime}$-axis, and the line of maximum dip is parallel to the $\mathrm{X}^{\prime}-\mathrm{Z}$ plane as shown in Fig. 1b. This axis transformation does not change the nature of the plane wave. However, it is easy to see that the 3D problem in Fig. 1b now can be represented by the 2D model in Fig. 1c. Therefore, it can be generalized that for a plane wave across one joint plane and one joint set, the 3D problem can be simply represented by a 2D model, as long as the joint angle in 2D adopts the maximum angle with respect to the wave direction. For a plane with apparent dip angles $\theta$ and $\varphi$ on $\mathrm{X}-\mathrm{Z}$ and $\mathrm{Y}-\mathrm{Z}$ planes, the maximum dip angle $\theta^{\prime}$ on the $X^{\prime}-Z$ plane can be calculated as

$\theta^{\prime}=\arctan \sqrt{\tan ^{2} \theta+\tan ^{2} \varphi}$

However, when joints are not parallel or when two or more joint sets exist, such problems will remain as $3 \mathrm{D}$ issues.

Fig. 1 2D equivalence of 3D plane wave propagation across a single joint

\section{Determination of Mesh Size}

The accuracy of numerical results generally increases with decreasing mesh size. However, with an extremely fine mesh size, substantial computational time will be consumed. Therefore, it is necessary to determine a reasonable mesh size to achieve a balance between computation efficiency and accuracy (Chen et al. 2000b). Parametric studies on mesh size were therefore carried out for $\mathrm{P}$ wave propagation normally across a single joint.

Figure 2 shows the configuration of the 3DEC model used in the study for normally and obliquely incident plane wave propagation across a single joint and a joint set. $\theta$ is the apparent joint angle on the $\mathrm{X}-\mathrm{Z}$ plane, and $\varphi$ on the $\mathrm{Y}-\mathrm{Z}$ plane. $n$ and $s$ are the joint number and joint spacing of the joint set. For normally incident plane wave propagation across joints, the angles $\theta$ and $\varphi$ are set to be zero. When a single joint is to be modeled, $n$ is equal to 1 . The measured point $\mathrm{A}$ is along the center line, $0.35 \mathrm{~m}$ away from the last joint plane. For normally incident wave propagation, the ratio of the maximum absolute value of the particle velocity in the $\mathrm{Z}$ direction at the measured point $\mathrm{A}$ to the incident wave amplitude defines the transmission coefficient $\left(\left|T_{1 \mathrm{p}}\right|\right.$ for incident $\mathrm{P}$ wave and $\left|T_{1 \mathrm{~s}}\right|$ for incident $\mathrm{S}$ wave). For obliquely incident $\mathrm{P}$ wave propagation, that ratio is considered as the transmission coefficient in the $\mathrm{Z}$ direction $\left(\left|T_{\mathrm{zp}}\right|\right)$. These definitions are the same as those used in analytical solutions by Cai and Zhao (2000).

In this study on the determination of mesh size, nonreflection boundary conditions are applied to the front and end boundaries in the $\mathrm{Z}$ direction, while the velocity of grid points of side boundaries are fixed at zero in the $\mathrm{X}$ and $\mathrm{Y}$ directions. For the meshing method adopted in this 3DEC modeling, the mesh size is controlled by the average length of tetrahedral zones. The mesh ratio $(l r)$, which is defined as the ratio of the average length of tetrahedral zones to the incident wave length, is used as the controlling parameter.

The properties of rock material and joints in this 3DEC modeling are the same as those adopted in the UDEC modeling by Zhu et al. (2011c), and they are reproduced in Table 1.

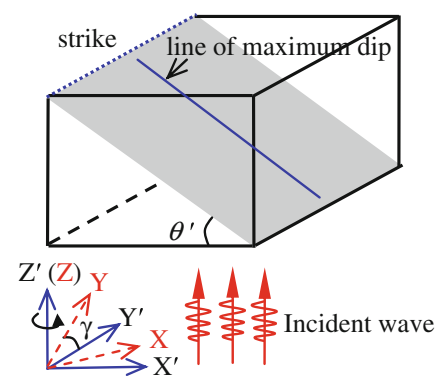

(b)

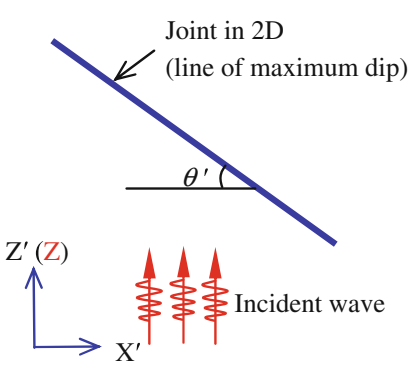

(c) 
Fig. 2 Configuration of 3DEC model of wave propagation across a joint set

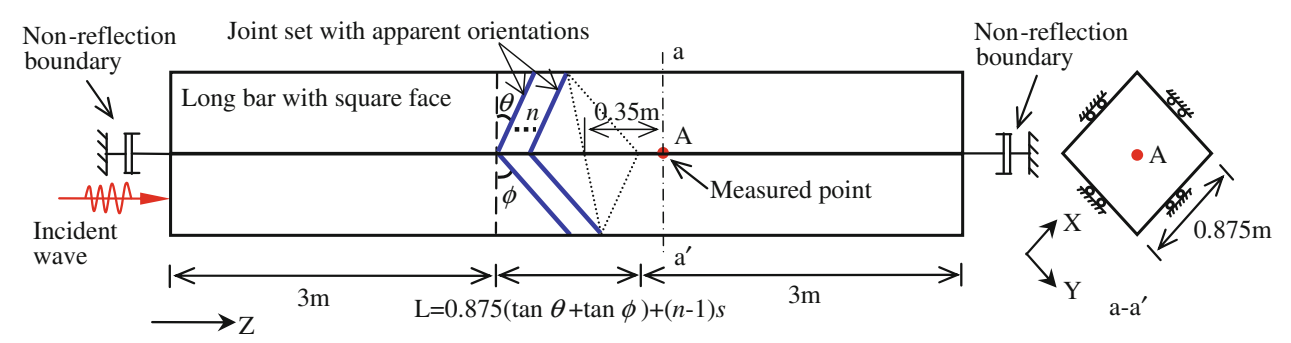

Table 1 Properties of rock material and joints in 3DEC modeling (Zhu et al. 2011a)

\begin{tabular}{ll}
\hline Properties & Value \\
\hline Density of rock material $\rho\left(\mathrm{kg} / \mathrm{m}^{3}\right)$ & 2,120 \\
$\begin{array}{l}\text { Young's modulus of rock material } \\
E(\mathrm{GPa})\end{array}$ & 27.9 \\
Poisson's ratio of rock material $v$ & 0.3 \\
Normal stiffness of joints $k_{n}(\mathrm{GPa} / \mathrm{m})$ & $1,5,10,20,50,100,200$ \\
Shear stiffness of joints $k_{s}(\mathrm{GPa} / \mathrm{m})$ & $\begin{array}{c}0.5,1,2,5,10,20,50,100, \\
200\end{array}$ \\
\hline
\end{tabular}

Figure 3 presents $\left|T_{1 \mathrm{p}}\right|$ versus joint normal stiffness $k_{n}$ for normally incident $\mathrm{P}$ wave propagation across a single joint with different mesh ratio $(l r=1 / 16,1 / 24,1 / 32,1 / 48$, and 1/96), where the incident wave is a one-cycle incident wave with amplitude $0.1 \mathrm{~m} / \mathrm{s}$ and frequency $1,000 \mathrm{~Hz}$. The modeling results are compared with analytical solutions of Pyrak-Nolte et al. (1990). It can be seen that the mesh ratio should be smaller than $1 / 32$ in order to obtain sufficiently accurate numerical results. To achieve a balance between computation efficiency and accuracy, the mesh ratio is set to be $1 / 48$ in all the modeling studies of the later sections.

\section{Verification of 2D Equivalence of Plane Wave Propagation Across a Single Joint with 3DEC}

In order to verify the $2 \mathrm{D}$ equivalence (Sect. 2) of plane wave propagation across a single joint, the angle $\theta^{\prime}$ is fixed at $45.53^{\circ}$, which can be achieved by different combinations of $\theta$ and $\varphi$ according to Eq. (1). In the present study, five different combinations of $(\theta, \varphi),(8.0,45.25),(16.0,44.35)$, (24.0, 42.5), (32.0, 38.8), and (40.0, 30.0), were adopted (Fig. 2). The joint stiffness $k_{n}$ and $k_{s}$ are equal to $20 \mathrm{GPa} / \mathrm{m}$. The other properties of jointed rock mass are the same as those in Table 1. A one-cycle incident wave with amplitude $0.1 \mathrm{~m} / \mathrm{s}$ and frequency $1,000 \mathrm{~Hz}$ is adopted at the front boundary in the $\mathrm{Z}$ direction as the incident wave. Nonreflection boundary conditions are applied at the side boundaries in the $\mathrm{X}-\mathrm{Y}$ plane and end boundary in the $\mathrm{Z}$ direction.

Figure 4 shows $\left|T_{\mathrm{zp}}\right|$ at different combinations of $(\theta, \varphi)$, giving a fixed $\theta^{\prime}$ of $45.53^{\circ}$. It can be seen that the

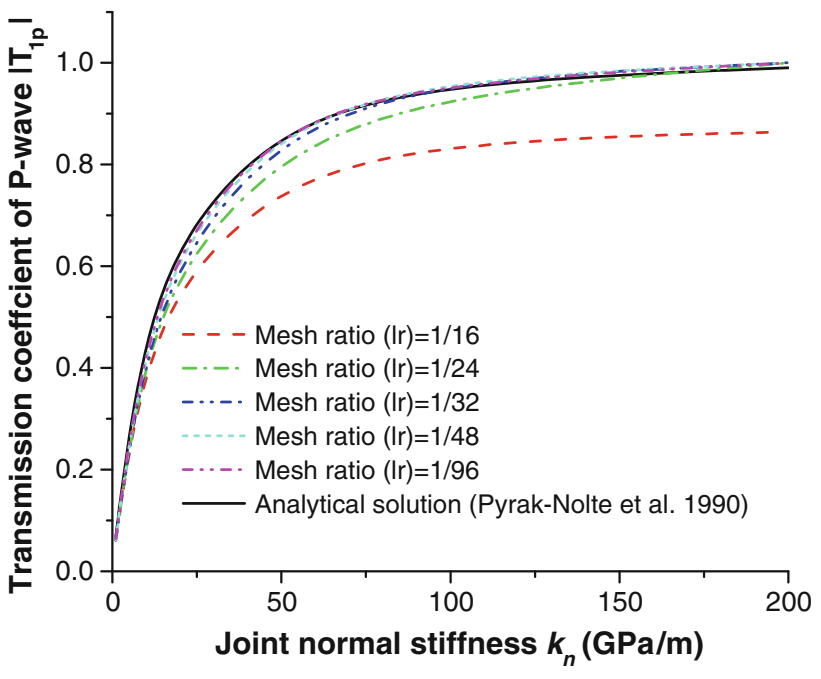

Fig. $3\left|T_{1 \mathrm{p}}\right|$ versus $k_{n}$ for normally incident $\mathrm{P}$ wave propagation across a single joint with different mesh ratio

magnitudes of $\left|T_{\mathrm{zp}}\right|$ vary little for different combinations of $(\theta, \varphi)$ when $\theta^{\prime}$ is constant. This indicates that the results obtained by 3DEC on plane wave propagation across a joint in a 3D space are equivalent to the analytical solutions in 2D space, which can be obtained from 3D spatial configuration, as suggested in Sect. 2.

\section{Normally Incident $P$ and $S$ Waves Across a Single Joint and a Joint Set}

For normally incident $\mathrm{P}$ wave propagation across a single joint, it is assumed that the joint normal stiffness $k_{n}$ is equal to the joint shear stiffness $k_{s}$. This assumption is also adopted in other cases of 3DEC modeling. A one-cycle sinusoidal incident $\mathrm{P}$ wave with amplitude $0.1 \mathrm{~m} / \mathrm{s}$ and frequency $1,000 \mathrm{~Hz}$ is normally applied at the front boundary, while non-reflection boundary conditions are applied at the end boundary in the $\mathrm{Z}$ direction. The velocity of grid points of side boundaries are fixed at zero in the $X$ and $\mathrm{Y}$ directions. Figure 5 shows the variation of the transmission coefficients $\left(\left|T_{1 \mathrm{p}}\right|\right)$ with stiffness $k_{n}$. It can be seen that the results obtained by the 3DEC agree well with the analytical solutions (Pyrak-Nolte et al. 1990) and UDEC modeling results (Zhu et al. 2011a). 


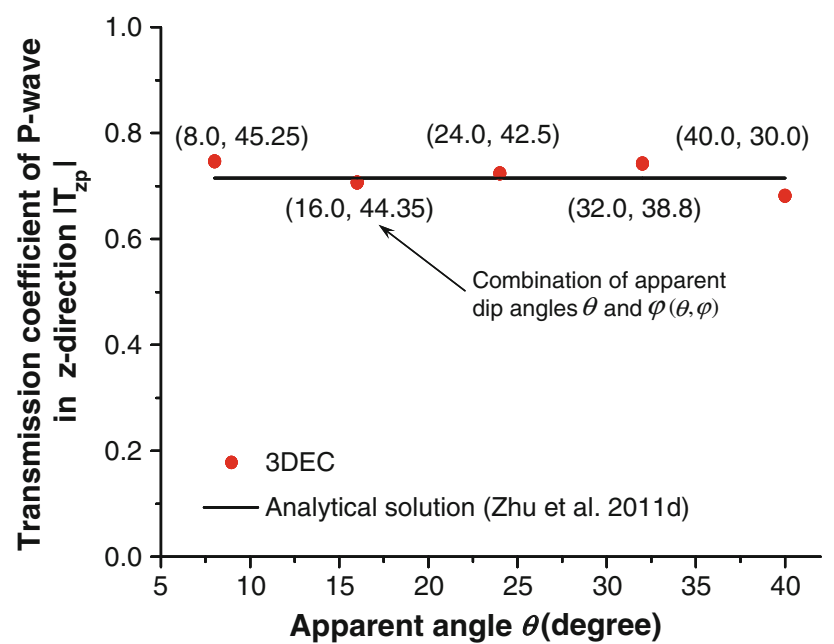

Fig. $4\left|T_{\mathrm{zp}}\right|$ of different combinations of $(\theta, \varphi)$ when $\theta^{\prime}$ is fixed at $45.53^{\circ}$

The computational model for an $\mathrm{S}$ wave is the same as that for a normally incident $\mathrm{P}$ wave propagation across a single joint, except that the applied incident wave is an $\mathrm{S}$ wave with amplitude $0.1 \mathrm{~m} / \mathrm{s}$ and frequency $1,000 \mathrm{~Hz}$, noreflection boundary conditions are applied at side boundaries, and the effect of shear joint stiffness on $\mathrm{S}$ wave propagation is studied. Figure 6 presents transmission coefficients $\left(\left|T_{1 \mathrm{~s}}\right|\right)$ versus $k_{s}$. It can be seen that the results obtained by the 3DEC again closely match the analytical solutions (Pyrak-Nolte et al. 1990) and UDEC modeling results (Zhu et al. 2011a).

The frequency of the incident wave has been shown by Zhao and Cai (2001) and Li and Ma (2010) to be a nonignorable parameter when studying wave transmission across joints. Therefore, transmissions of $\mathrm{P}$ waves normally across a single joint in terms of different wave frequencies

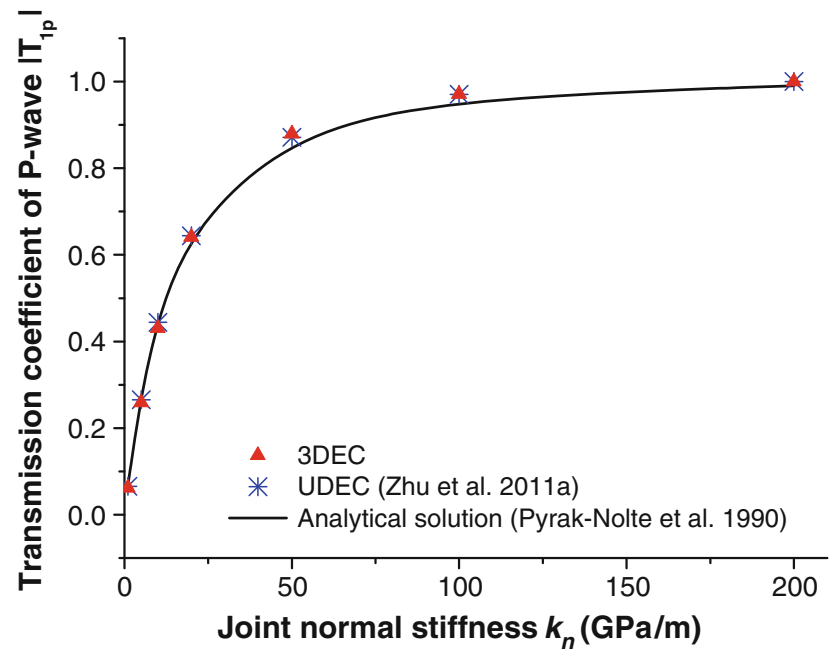

Fig. $5\left|T_{1 \mathrm{p}}\right|$ versus $k_{n}$ for normally incident $\mathrm{P}$ wave propagation across a single joint

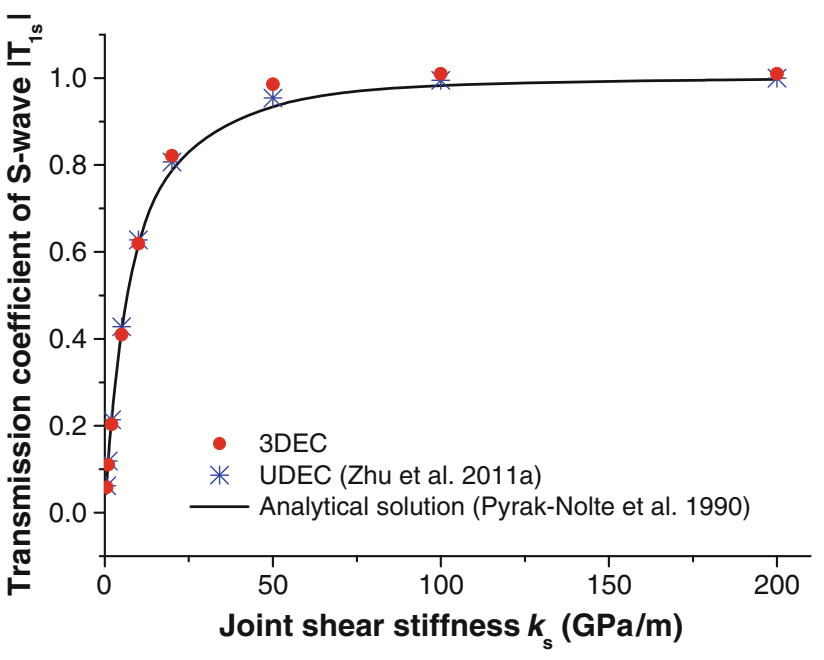

Fig. $6\left|T_{1 \mathrm{~s}}\right|$ versus $k_{s}$ for normally incident $\mathrm{S}$ wave propagation across a single joint

were numerically modeled in this study. In this modeling, the model length is not fixed but increases with decreasing of incident wave frequency to accurately afford the peak particle velocity (PPV) of the measured point A. The mechanical properties of rock and joint are the same as those listed in Table 1 except that the joint normal stiffness $k_{n}\left(=k_{s}\right)$ was separately fixed at 10,50 , and $100 \mathrm{GPa}$. The frequency of the incident $\mathrm{P}$ wave with fixed amplitude $0.1 \mathrm{~m} / \mathrm{s}$ at the front boundary in the $\mathrm{Z}$ direction was separately assumed to be 5,10,20,50,100,200,500, and $1,000 \mathrm{~Hz}$. The conditions of other boundaries are the same as those in the study of the normally incident $\mathrm{P}$ wave propagation across a single joint. Figure 7 shows the transmission coefficients $\left(\left|T_{1 \mathrm{p}}\right|\right)$ as a function of frequency, form which it can be seen that the results obtained by the 3DEC again agree well with the analytical solutions (Pyrak-Nolte et al. 1990) and UDEC modeling results.

As a result of multiple wave reflections among different joints, wave propagation across a joint set is more complicated (Cai and Zhao 2000). In the 3DEC computation of normally incident $\mathrm{P}$ wave propagation across a joint set, the joint stiffness $k_{n}$ and $k_{s}$ are fixed at $50 \mathrm{GPa}$. The other rock material and wave properties are the same as those in the simple joint model. Non-dimensional joint spacing $(\xi)$, which is defined as the ratio of the joint spacing to the incident $\mathrm{P}$ wave length, is adopted in this study. It is assumed that the number of joints is equal to 2,5 , and 8 in each joint set, and for each joint number setting, $\xi$ is designed to take the value $0.02,0.05,0.1,0.2,0.3$, and 0.4 . In this study of normally incident $\mathrm{P}$ wave propagation across a joint set, the boundary conditions of the 3DEC model are the same as those in the study of normally incident $\mathrm{P}$ wave propagation across a single joint. Figure 8 shows $\left|T_{1 \mathrm{p}}\right|$ as a function of $\xi(0.02,0.05,0.1,0.2,0.3$, and 


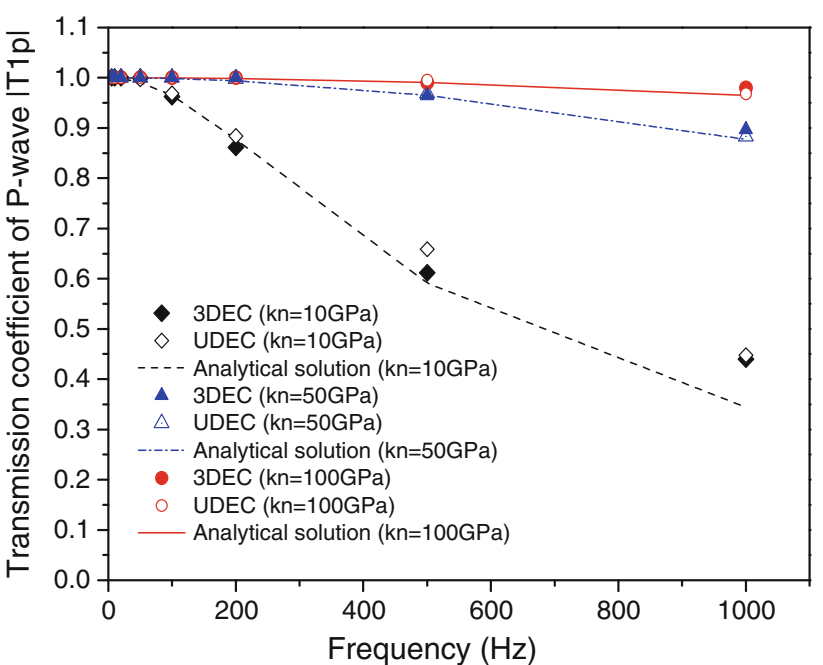

Fig. $7\left|T_{1 \mathrm{p}}\right|$ versus wave frequency for normally incident $\mathrm{P}$ wave propagation across a joint set

$0.4)$ for different numbers of joints $(2,5$, and 8$)$. It can be seen that the results obtained by the 3DEC agree well with those of the analytical solutions and UDEC modeling results (Zhu et al. 2011a, c).

\section{Obliquely Incident P Wave Across a Single Joint and a Joint Set}

When the wave is obliquely incident upon joints, complex wave transformation occurs, producing reflected and refracted waves ( $\mathrm{Li}$ and $\mathrm{Ma}$ 2010). In the 3DEC modeling of obliquely incident $\mathrm{P}$ wave propagation across a single joint, it is assumed that the joint stiffness $k_{n}$ and $k_{s}$ are fixed at $20 \mathrm{GPa}$. The combinations of $\theta, \varphi$, and $\theta^{\prime}$ (Sect. 2) are shown in Table 2 . The boundary conditions are the same as those in the study to verify the $2 \mathrm{D}$ equivalence of plane wave propagation across a single joint in Sect. 4 . The other input properties of rock material and incident wave are the same as those in Sects. 3 and 5. Figure 9 shows $\left|T_{\mathrm{zp}}\right|$ at different incident angles $\left(\theta\right.$ and $\varphi$ in 3D cases, $\theta^{\prime}$ in 2D cases). Thus, the 3DEC modeling results agree well with those of UDEC modeling and analytical solutions (Zhu et al. 2011a, d). However, at small incident angles, the numerical results are slightly lower than those of analytical solutions.

The complexity of obliquely incident wave propagation across a joint set increases because of multiple wave reflection among joints and wave transformation at joints. In this modeling verification study, a half-cycle sinusoidal incident $\mathrm{P}$ wave with amplitude $0.1 \mathrm{~m} / \mathrm{s}$ and frequency $1,000 \mathrm{~Hz}$ is applied at the front boundary in the $\mathrm{Z}$ direction. Non-reflection boundary conditions are applied at the side boundaries in the $\mathrm{X}-\mathrm{Y}$ plane and at the end boundary in the



Fig. $8\left|T_{1 \mathrm{p}}\right|$ versus $\xi$ for normally incident $\mathrm{P}$ wave propagation across a joint set

$\mathrm{Z}$ direction. The non-dimensional joint spacing $(\xi)$ is designed to adopt the value $0.02,0.05,0.1,0.2,0.3,0.5$, and 0.7. Figure 10 shows $\left|T_{\mathrm{zp}}\right|$ as a function of the $\xi$ for different numbers of joints. It can be seen that the agreement between 3DEC modeling results and analytical solutions is generally good. However, the $\left|T_{\mathrm{zp}}\right|$ values of 3DEC modeling results are larger than those of analytical solutions when non-dimensional joint spacing $\xi$ is at least 0.5 , and they are little smaller when $\xi$ is no greater than 0.1 .

\section{A Case Study}

To verify the capability of 3DEC to effectively model the wave propagation in jointed rock masses further, we analyzed a large-scale decoupled explosion test performed in Älvdalen, Sweden, site of the existing Klotz Group tunnel, with the purpose of evaluating a design concept for underground ammunition storage in bedrock in September 2001.

Table 2 Angle setting for modeling of a $\mathrm{P}$ wave obliquely transmitted through a single joint

\begin{tabular}{llll}
\hline No. & \multicolumn{2}{l}{ Apparent angles in 3D case $\left(^{\circ}\right)$} & Angle $\theta^{\prime}$ in 2D case $\left(^{\circ}\right)$ \\
\cline { 2 - 3 } & $\theta$ & $\varphi$ & \\
\hline 1 & 10 & 20 & 22.02 \\
2 & 20 & 30 & 34.31 \\
3 & 30 & 40 & 45.53 \\
4 & 40 & 50 & 55.55 \\
5 & 50 & 60 & 64.56 \\
6 & 60 & 70 & 72.89 \\
\hline
\end{tabular}




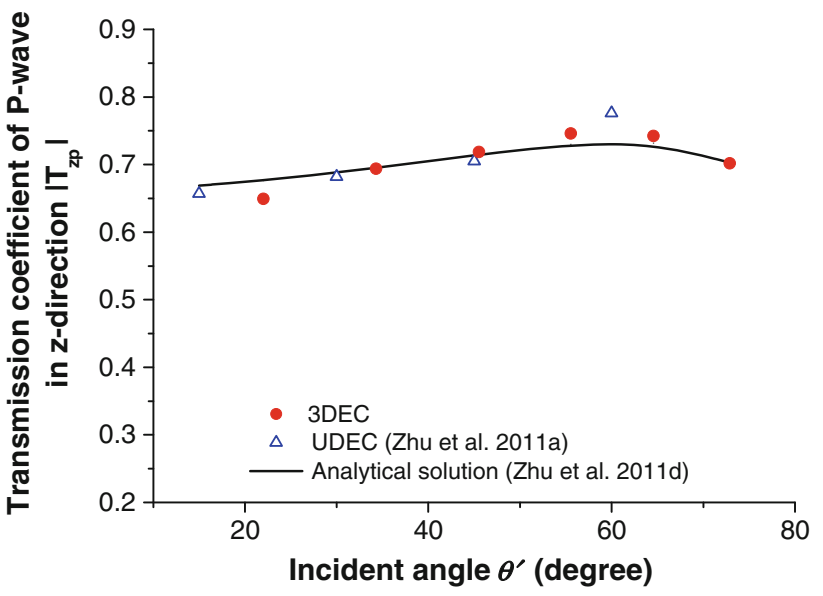

Fig. $9\left|T_{\mathrm{zp}}\right|$ versus wave incident angle for obliquely incident $\mathrm{P}$ wave propagation across a single joint

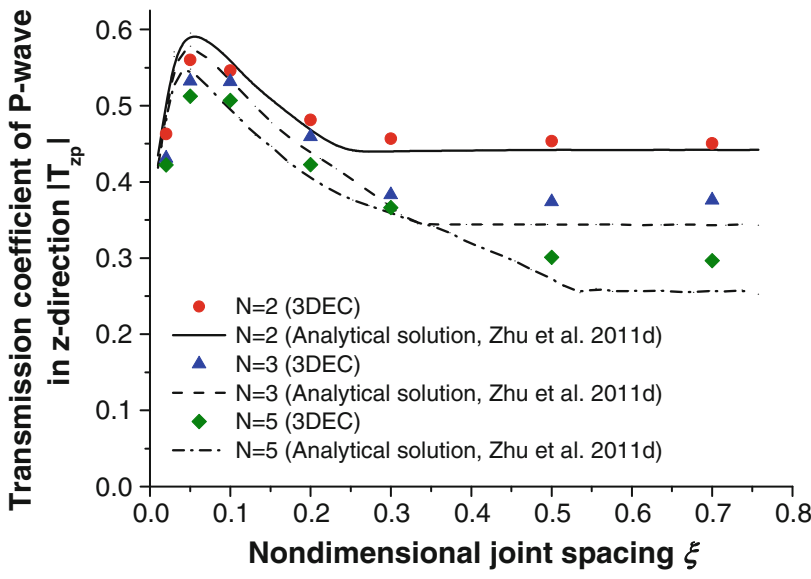

Fig. $10\left|T_{\mathrm{zp}}\right|$ versus $\xi$ for obliquely incident $\mathrm{P}$ wave propagation across a joint set
Figure 11 shows a cross section of the test site containing the geometries of the explosion chamber and adjacent tunnels, ground shock instrumentations, rock layer distribution etc. and the configuration of the 3DEC model of the zone under study. The width and height of this chamber are $8.8 \mathrm{~m}$ and $4.2 \mathrm{~m}$, respectively. In the test, the ground shock up the explosion chamber and the pressure at the explosion chamber roof were recorded. Therefore, in this case study, the 3DEC numerical modeling merely considered the shock wave propagation in the zone up the explosion chamber where the recorded time-pressure history (Fig. 12) at the explosion chamber roof in the test was employed as velocity boundary conditions in the 3DED model through exchange. This explosion test was performed in an almost closed chamber. Therefore, in accordance with the research by Zhou et al. (2000) showing that the PPV in closed chamber conditions could be two times than that in free field conditions at the chamber surface because of reflection, the relation between pressure and velocity at the explosion chamber roof in this case can be expressed as

$v_{n}=2 \sigma_{n} / \rho C_{p}$

where $\sigma_{n}$ is the normal stress, $\rho$ is the mass density, $C_{p}$ is the speed of pressure wave propagation through the medium, and $v_{n}$ is the particle velocity. The zero-velocity and non-reflection boundary conditions were applied at the lateral and top boundaries of the 3DEC model, respectively.

The rock at the site is of high strength with Young's modulus of $94.75 \mathrm{GPa}$ and Poisson's ratio of 0.27 . The density of the rock is $2,620 \mathrm{~kg} / \mathrm{m}^{3}$. The rock fractures are oriented in three directions and their orientation and mechanical parameters are listed in Table 3.
Fig. 11 Cross section of test site and configuration of 3DEC model of zone adopted in this case study

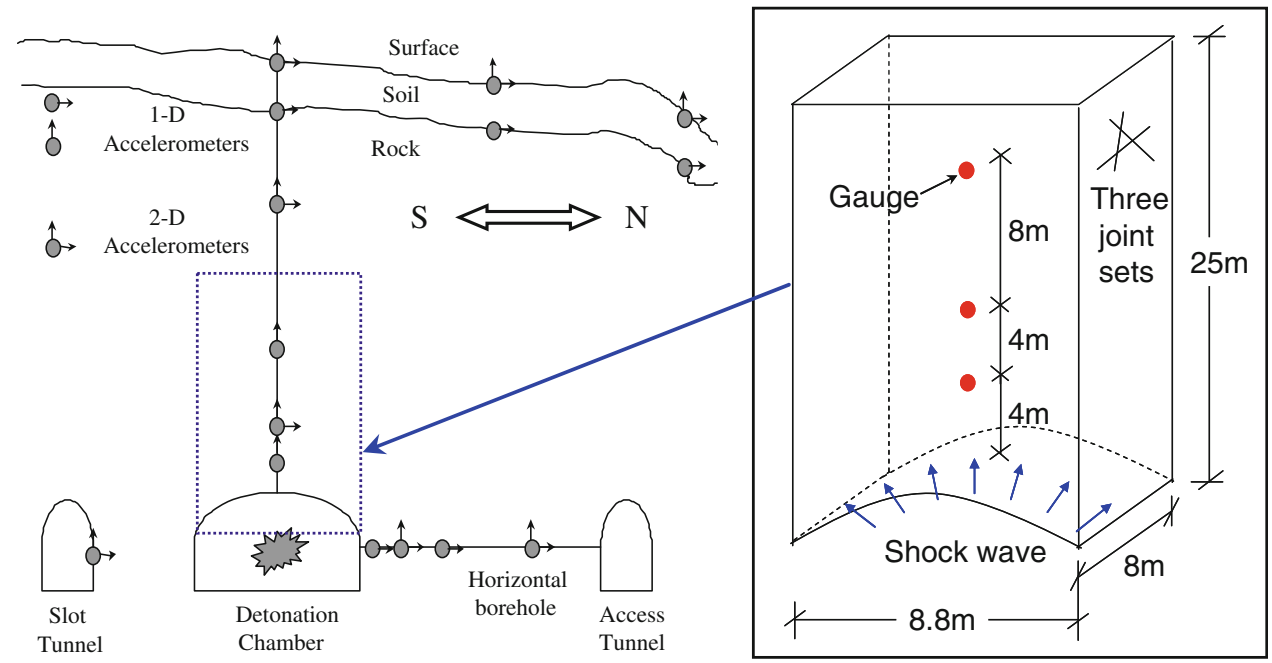




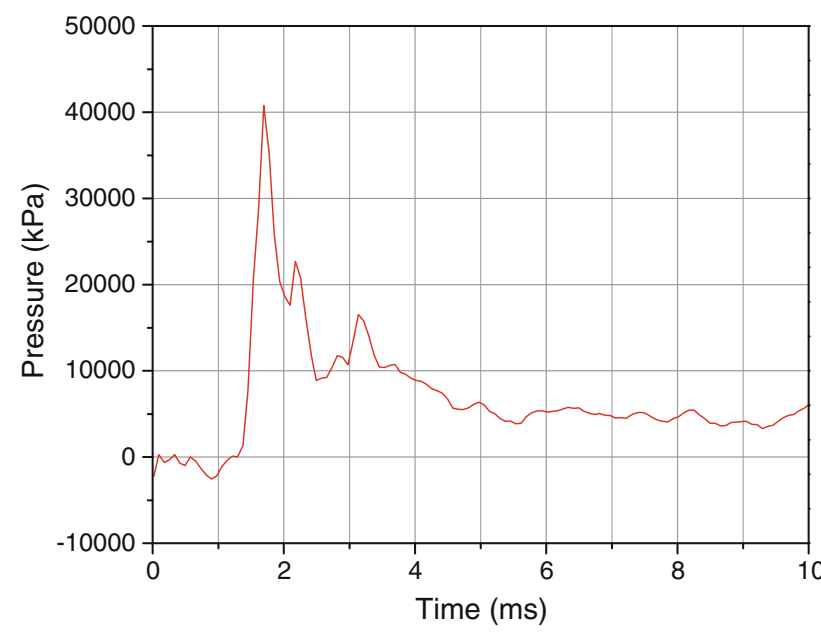

Fig. 12 Recorded time-pressure history at explosion chamber roof in test

Table 3 Spatial and mechanical properties of rock joints in the Klotz tunnel

\begin{tabular}{|c|c|c|c|c|c|}
\hline \multicolumn{2}{|c|}{$\begin{array}{l}\text { Fracture } \\
\text { orientation }\end{array}$} & \multirow[t]{2}{*}{$\begin{array}{l}\text { Fracture } \\
\text { distance }(m)\end{array}$} & \multirow[t]{2}{*}{$k_{n}(\mathrm{GPa})$} & \multirow[t]{2}{*}{$k_{s}(\mathrm{GPa})$} & \multirow[t]{2}{*}{$\begin{array}{l}\text { Friction } \\
\text { angle }\left({ }^{\circ}\right)\end{array}$} \\
\hline Dip & Strike & & & & \\
\hline $47^{\circ} / \mathrm{SW}$ & $\mathrm{N} 47^{\circ} \mathrm{W}$ & 0.6 & 128.62 & 50.67 & 30 \\
\hline $5 \% \mathrm{SE}$ & $\mathrm{S} 12^{\circ} \mathrm{W}$ & 1.2 & 64.31 & 25.34 & 30 \\
\hline $35^{\circ} / \mathrm{NE}$ & $\mathrm{N} 2^{\circ} \mathrm{W}$ & 0.6 & 128.62 & 50.67 & 30 \\
\hline
\end{tabular}

Studies have shown that the PPV is the most representative parameter when describing the ground motion and tunnel response (Dowding 1984). Therefore, the velocities of gauges shown in Fig. 11 were recorded in the 3DEC modeling process and their PPVs were compared to those obtained in the test. Considering the credibility of this comparison, an empirical formula for the decoupled explosion in terms of the PPV is adopted and can be expressed in the following form (Johnson and Rozen 1988; Zhou and Jenssen 2009):

$P P V=f_{d} H(S D)^{-n}$

where $S D=d / Q^{1 / 3}$ is the scaled distance, $\mathrm{m} / \mathrm{kg}^{1 / 3} ; d$ is the actual distance from the detonation point, $\mathrm{m}$; and $Q$ is the charge weight, $\mathrm{kg} . H$ is the initial value estimated by the equation $H=0.5 C^{2.17} /(\rho C)$, where $\rho$ is the rock mass density, $\mathrm{kg} / \mathrm{m}^{3}$; and $C$ is the shock wave velocity, $\mathrm{m} / \mathrm{s} . n$ is the attenuation coefficient and typically equals 1.5 for hard rock. $f_{d}$ is the decoupling factor and can be derived via the equation $f_{d}=0.025(\omega)^{n / 3}$, where $\omega$ is the loading density and equals $10 \mathrm{~kg} / \mathrm{m}^{3}$ in this case. It is assumed that the value of $n$ is 1.5 in the predictions of PPV via the empirical formula in this case study.

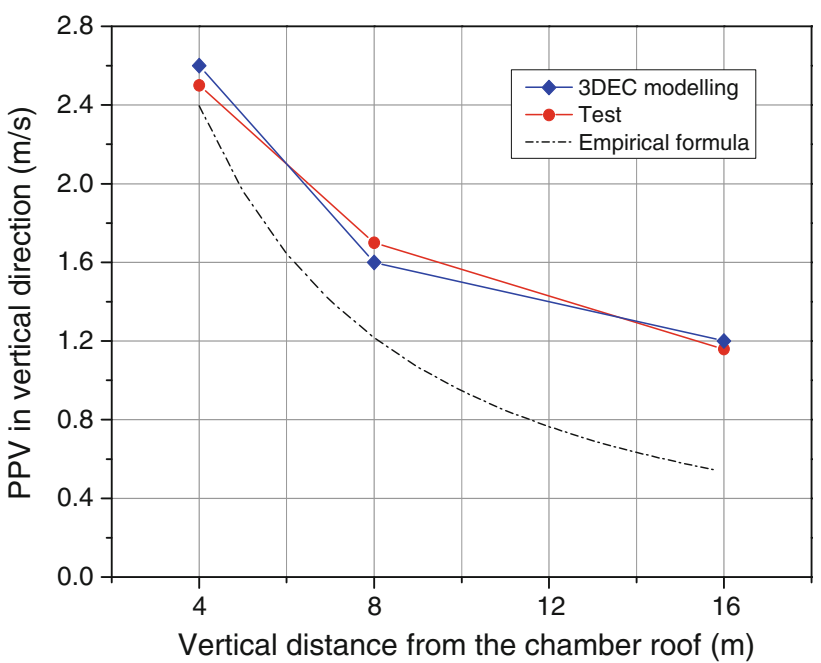

Fig. 13 Comparison of peak particle velocities according to 3DEC modeling, test, and empirical formula (Johnson and Rozen 1988; Zhou and Jenssen 2009)

Figure 13 shows the comparison of PPV up the explosion chamber according to the 3DEC modeling, test, and empirical formula. It can be seen that the PPVs predicted by the empirical formula are smaller compared to 3DEC modeling results and test data. This difference is mainly caused by the fact that the values of properties such as $n$ and $f_{d}$ are obtained according to experiment from lots of explosion tests and could be inaccurate for this case. However, the predictions of PPV via the empirical formula demonstrate the availability of test data and credibility of the 3DEC modeling results in this case study. The 3DEC modeling results agree well with the test data. Therefore, it can be concluded that $3 \mathrm{DEC}$ has the capability to model the shock wave propagation in jointed rock masses where the actual rock fractures are represented in the 3DEC model.

\section{Discussion and Conclusions}

For 3DEC modeling of normally incident wave propagation across a single joint and a joint set, the velocity of grid points of side boundaries are fixed in the $\mathrm{X}$ and $\mathrm{Y}$ directions. The modeling results are accurate because the wave propagation direction is parallel to the side boundaries and there are no waves incident upon the side boundaries; therefore, there is no wave reflection at the side boundaries. However, for obliquely incident wave propagation across joints, as a result of wave reflection at joints, reflected waves will be incident upon the side boundaries. In order to eliminate the reflection waves from the side boundaries to guarantee the computation accuracy, viscous boundaries are used in 3DEC. 
Fig. 14 Zone layers between parallel joints

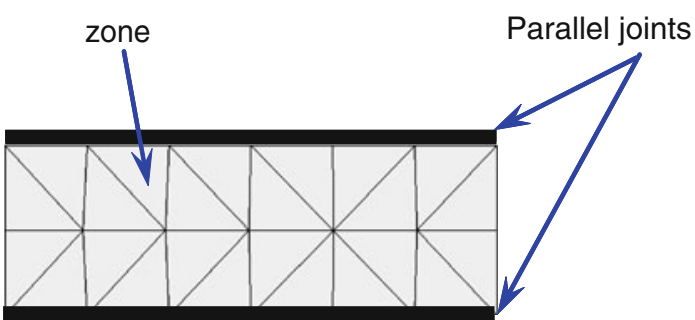

(b) Two layers zones

(a) One layer zones

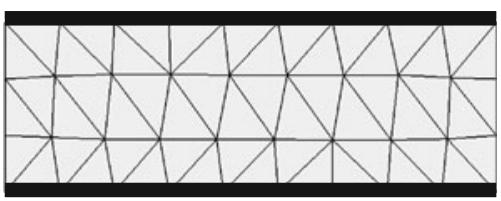

(c) Three layers zones

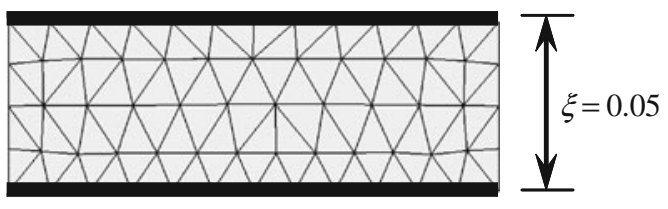

(d) Four layers zones
In the modeling of obliquely incident wave propagation across a joint set, when $\xi$ is smaller than 0.1 and larger than 0.5 , there are correspondingly large differences between analytical solutions and 3DEC modeling results. For the former range $(\xi \leq 0.1)$, this is because that spacing between two parallel joints is very small and only one layer zone can be generated in the 3DEC model as shown in Fig. 14a for the case of $\xi=0.05$ when the mesh ratio $(l r)$ is assumed to be $1 / 48$. However, this difference is decreased when the zones generated between these two parallel joints are increased to not less than three layers as shown in Fig. 14. This is an additional mesh size controlling factor to the general requirement of $l r<1 / 32$ (Sect. 3) in order to obtain reasonably accurate results. For the latter range $(\xi \geq 0.5)$, this is because in the 3DEC model the joint distribution length $L \quad(L=0.875(\tan \theta+\tan \varphi)+(n-1) s)$ increases with increasing of $n$ or $s$, as depicted in Fig. 2, which leads to more wave reflection on the side boundaries when the width of square bar is fixed $(0.875 \mathrm{~m})$. Moreover, the viscous boundaries adopted in this modeling are incapable of absorbing all the incident waves, especially for waves with small incident angle.

3D plane wave propagation across a single joint or a joint set can be treated equivalently to a corresponding $2 \mathrm{D}$ case, as shown both analytically and numerically. However, it should be noted that when the incident wave is not a plane wave (e.g., spherical wave, cylindrical wave) or there are unparallel joints and joint sets, a 3D case cannot be equivalent to a $2 \mathrm{D}$ case.

Through the 3DEC modeling of wave propagation across rock joints performed in this study, the following conclusions are drawn:

1. Plane wave propagation across a single joint and a joint set in a 3D space can be treated and transformed to a corresponding $2 \mathrm{D}$ case.
2. In 3DEC modeling of wave propagation problems, mesh ratio should be generally smaller than $1 / 32$ to ensure the computational accuracy. In addition, with closely spaced joints, there should be at least three mesh layers between the joints.

3. For wave propagation across a single rock joint and a joint set with different incident wave types, joint stiffness, joint spacing, incident angles, and number of joints, the results obtained by 3DEC agree well with analytical solutions and UDEC modeling results. This verifies the capability of $3 \mathrm{DEC}$ to modeling wave propagation across a single joint and a joint set.

4. The case study of a large-scale decoupled explosion test, where three joint sets with different orientations were considered, further verifies the capability of $3 \mathrm{DEC}$ to model wave propagation in jointed rock masses in $3 \mathrm{D}$ space.

This study focused on some fundamental issues, especially on verification studies, in 3DEC modeling of wave propagation across rock joints. However, in reality, rock mass consists of underground structures. Therefore, further studies on wave propagation in jointed rock masses together with the interaction of built structures (tunnel and slopes) will be conducted.

Acknowledgments The research is financially supported by China Scholarship Council, Swiss National Science Foundation (200021116536), and the Fundamental Research Funds for the Central University in China (SWJTU11ZT33).

\section{References}

Barla G, Monacis G, Perino A, Hatzor YH (2010) Distinct element modelling in static and dynamic conditions with application to an underground archaeological site. Rock Mech Rock Eng $43: 877-890$ 
Brady BH, Hsiung SH, Chowdhury AH, Philip J (1990) Verification studies on the UDEC computational model of jointed rock. In: Rossmanith HP (ed) Mechanics of jointed and faulted rock. Balkema, Rotterdam, p 551-558

Cai JG, Zhao J (2000) Effects of multiple parallel fractures on apparent wave attenuation in rock masses. Int J Rock Mech Min Sci 37:661-682

Chen SG, Cai JG, Zhao J, Zhou YX (2000a) Discrete element modelling of underground explosions in jointed rock mass. Geotech Geol Eng 18:59-78

Chen SG, Zhao J, Makurat A, Madshus C (2000b) Mesh size influence on dynamic modelling. Fragblast Int J Blasting Fragm 4:164-174

Cundall PA (1971) A computer model for simulating progressive large scale movements in blocky rock systems. In: Proceedings Symp Int Soc Rock Mech. France, Nancy, p 11-18

Dowding CH (1984) Estimating earthquake damage from explosion testing of full-scale tunnels. Adv Tunn Technol Subsurf Use 4(3):113-117

Jiao YY, Zhang XL, Zhao J, Liu QS (2007) Viscous boundary of DDA for modeling stress wave propagation in jointed rock. Int $\mathrm{J}$ Rock Mech Min Sci 44:1070-1076

Johnson W, Rozen A (1988) Explosion in soils: the effects of soil properties on shock attenutation. In: Minutes of the 23rd DoD explosives seminar, VA, USA

Kendall K, Tabor D (1971) An ultrasonic study of the area of contact between stationary and sliding surfaces. Proc Roy Soc 323:321-340

Lei WD, Hefny AM, Yan S, Teng J (2007) A numerical study on 2-D compressive wave propagation in rock masses with a set of joints along the radial direction normal to the joints. Comput Geotech 34:508-523

Lemos JV (1987) A distinct element model for dynamic analysis of jointed rock with application to dam foundation and fault motion. PhD thesis, Minneapolis, USA, University of Minnesota

Li JC, Ma GW (2010) Analysis of blast wave interaction with a rock joint. Rock Mech Rock Eng 43:777-787

Li JC, Ma GW, Zhao J (2010) An equivalent viscoelastic model for rock mass with parallel joints. J Geophys Res 115. doi: 10.1029/2008JB006241

Perino A, Zhu JB, Li JC, Barla G, Zhao J (2010) Theoretical methods for wave propagation across jointed rock masses. Rock Mech Rock Eng 43:799-809
Pyrak-Nolte LJ, Myer LR, Cook NGW (1990) Anisotropy in seismic velocities and amplitudes from multiple parallel fractures. J Geophys Res 95:11345-11358

Schoenberg M (1980) Elastic wave behavior across linear slip interfaces. J Acoust Soc Am 68:1516-1521

Zhao J, Cai JG (2001) Transmission of elastic P-wave across single fractures with a nonlinear normal deformational behavior. Rock Mech Rock Eng 34:3-22

Zhao J, Zhou YX, Hefny AM, Cai JG, Chen SG, Li HB, Liu JF, Jain M, Foo ST, Seah CC (1999) Rock dynamics research related to cavern development for ammunition storage. Tunn Undergr Space Technol 14:513-526

Zhao J, Cai JG, Zhao XB, Li HB (2006a) Experimental study of ultrasonic wave attenuation across parallel fractures. Geomech Geoengin 1:87-103

Zhao J, Zhao XB, Cai JG (2006b) A further study of P-wave attenuation across parallel fractures with linear deformational behavior. Int J Rock Mech Min Sci 43:776-788

Zhao XB, Zhao J, Cai JG, Hefny AM (2008) UDEC modelling on wave propagation across fractured rock masses. Comput Geotech 35:97-104

Zhou YX, Jenssen A (2009) Internal separation distances for underground explosives storage in hard rock. Tunn Undergr Space Technol 24:119-125

Zhou YX, Seah CC, Guah EH, Foo ST, Wu YK, Ong PF (2000) Considerations for ground vibrations in underground blasting. In: Tunnels and underground structures. Balkema, Rotterdam, p 313-316

Zhu JB, Deng XF, Zhao XB, Zhao J (2011a) A numerical study on wave propagation across multiple joint sets in rock masses with UDEC. Rock Mech Rock Eng (submitted)

Zhu JB, Zhao GF, Zhao XB, Zhao J (2011b) Validation study of the distinct lattice spring model (DLSM) on P-wave propagation across multiple parallel joints. Comput Geotech 38:298-304

Zhu JB, Zhao XB, Li JC, Zhao GF, Zhao J (2011c) Normally incident wave transmission across one joint set with virtual wave source method. J Appl Geophys 73:283-288

Zhu JB, Zhao XB, Zhao GF, Li JC, Zhao J (2011d) Obliquely incident wave transmission across one joint set with virtual wave source method. J Appl Geophys (submitted) 